\title{
Accuracy of analyzed temperatures, winds and trajectories in the Southern Hemisphere tropical and midlatitude stratosphere as compared to long-duration balloon flights
}

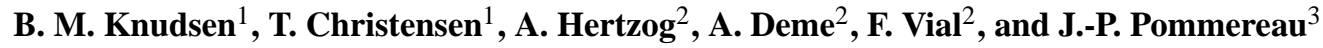 \\ ${ }^{1}$ Danish Meteorological Institute, Copenhagen, Denmark \\ ${ }^{2}$ Laboratoire de Météorologie Dynamique du Centre National de la Recherche Scientifique, France \\ ${ }^{3}$ Service d'Aeronomie du Centre National de la Recherche Scientifique, France
}

Received: 10 May 2006 - Published in Atmos. Chem. Phys. Discuss.: 7 August 2006

Revised: 7 November 2006 - Accepted: 22 November 2006 - Published: 4 December 2006

\begin{abstract}
Eight super-pressure balloons floating at constant level between 50 and $80 \mathrm{hPa}$ and three Infra-Red Montgolfier balloons of variable altitude $(15 \mathrm{hPa}$ daytime, 40 $80 \mathrm{hPa}$ night time) have been launched at $22^{\circ} \mathrm{S}$ from Brazil in February-May 2004 in the frame of the HIBISCUS project. The flights lasted for 7 to 79 days residing mainly in the tropics, but some of them passed the tropical barrier and went to southern midlatitudes. Compared to the balloon measurements just above the tropical tropopause the ECMWF operational temperatures show a systematic cold bias of $0.9 \mathrm{~K}$ and the easterly zonal winds are too strong by $0.7 \mathrm{~m} / \mathrm{s}$. This bias in the zonal wind adds to the ECMWF trajectory errors, but they still are relatively small with e.g. about an error of $700 \mathrm{~km}$ after 5 days. The NCEP/NCAR reanalysis trajectory errors are substantially larger (1300 km after 5 days). In the southern midlatitudes the cold bias is the same, but the zonal wind bias is almost zero. The trajectories are generally more accurate than in the tropics, but for one balloon a lot of the calculated trajectories end up on the wrong side of the tropical barrier and this leads to large trajectory errors.
\end{abstract}

\section{Introduction}

This study provides a new intercomparison between the operational ECMWF (and to some extent the NCEP/NCAR reanalysis) data and independent in-situ measurements valid for the southern tropics and extratropics. These new results are important for research studies which depend on the accuracy of assimilations systems such as for example chemical transport studies in the stratosphere do.

Correspondence to: B. M. Knudsen

(bk@dmi.dk)
The accuracy of analyzed temperatures in the tropical tropopause layer has been studied extensively, due to e.g. its influence on the stratospheric humidity. Simmons et al. (1999) found the operational ECMWF analyses from $1996-1998$ to have a standard-level bias of the order of $0.5^{\circ} \mathrm{C}$ or less compared to radiosondes. The temperature minima were, however, substantially overestimated, partially due to a $20 \mathrm{hPa}$ vertical resolution of the model back then.

From three long-duration super-pressure balloon flights launched at $0.1^{\circ} \mathrm{N}$ from Ecuador, Vial et al. (2001) studied the accuracy of both ECMWF temperatures and winds at around $60 \mathrm{hPa}$ from late August to mid October 1998 in the equatorial region. They found a warm bias of the ECMWF temperatures of about $0.5 \mathrm{~K}$ compared with longduration balloons. The easterly zonal winds were too strong by $2.4 \mathrm{~m} / \mathrm{s}$, but this could be explained by the balloon Stokes drift due to a Rossby-gravity wave near the equator.

In the Stratospheric Processes And their Role in Climate (SPARC) Intercomparison of Middle Atmosphere Climatologies (SPARC, 2002; Randel et al., 2004a) several analyses and reanalyses were studied. Noteworthy is a $1-3 \mathrm{~K}$ warm bias of the tropical tropopause for the (UK)MO (Met Office), CPC (Climate Prediction Center), and NCEP (National Center for Environmental Prediction) analyses from 1992-1997. Randel et al. (2004b) found this still to be true for (UK)MO and NCEP in 2001-2002. Using GPS (Global Positioning System)-derived temperatures Gobiet et al. (2005) found an ECMWF cold bias of 1-2 K at the tropical tropopause in 2003-2004.

While past results for reanalyses still could be valid depending on changes in the observing system, the operational analyses are also subject to continuous model developments and past results may thus not reflect the current status.

Published by Copernicus GmbH on behalf of the European Geosciences Union. 


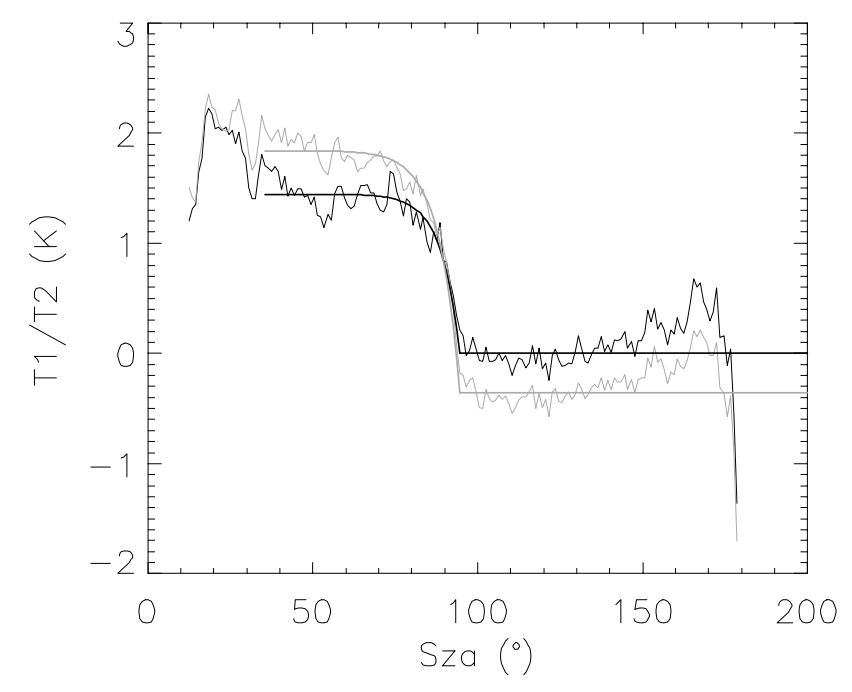

Fig. 1. Temperature variations on super-pressure balloon flights (at $50-80 \mathrm{hPa}$ ) as a function of the sun zenith angle. Measured temperatures (noisy curves) exhibit a warm bias during day, which is larger for the largest themistors (grey) than for the smallest ones (black). The temperatures measured with the largest thermistors also show a cold bias during night. The variations shown here are computed with respect to the night time temperatures measured with the smallest sensor (see text). (smooth curves) Correction applied to the raw measurements.

In this paper we compare operational ECMWF analyses to long-duration balloon launched from Bauru $\left(22^{\circ} \mathrm{S}, 49^{\circ} \mathrm{W}\right)$ in Brazil in February-May 2004 during the HIBISCUS campaign (Pommereau et al., 2006 ${ }^{1}$ ). We compare temperatures, horizontal winds, and trajectories. We primarily analyze data in the region just above the tropical tropopause (50-80 hPa). Trajectories based on NCEP/NCAR reanalyses are also compared. A paper on the ERA-40 reanalyses compared to longduration balloon flights back to 1988 will also be submitted to the HIBISCUS special issue (Christensen et al., 2006²).

\section{Long-duration balloon flights}

Eight super-pressure (BP=Ballon Pressuris) and three InfraRed Montgolfier (MIR) long duration balloons have been flown from Brazil during the HIBISCUS campaign (Pommereau et al., 2006, this special issue). One of the balloons (BP2) failed and a second one (BP3) experienced some problems of transmission which make the data useless. The BPs are spherical constant volume and therefore constant

\footnotetext{
${ }^{1}$ Pommereau, J.-P., Garnier, A., Goutail, F., et al.: An overview of the HIBISCUS campaign, Atmos. Chem. Phys. Discuss., in preparation, 2006.

${ }^{2}$ Christensen, T., Knudsen, B. M., Pommereau, J.-P., Letrenne, G., Hertzog, A., and Vial, F.: Validation of ECMWF ERA-40 tropical lower stratosphere temperatures and winds with long-duration balloon data, Atmos. Chem. Phys. Discuss., in preparation, 2006.
}

density (isopycnic) balloons made of trilaminated polyester. They were of two sizes: $10 \mathrm{~m}$ diameter flying around $55 \mathrm{hPa}$ $(19 \mathrm{~km})$ varying a little with the load and $8.5 \mathrm{~m}$ diameter at $75 \mathrm{hPa}(18 \mathrm{~km})$ that is at or a little above the cold point tropopause. Two of the 6 HIBISCUS BP flights stayed in the tropics, while the 4 others drifted to the southern-hemisphere mid-latitudes.

The scientific payload on BP flights, called Rumba, carries a GPS for location $( \pm 10 \mathrm{~m})$ and wind $( \pm 0.01 \mathrm{~m} / \mathrm{s})$, a pressure $( \pm 0.6 \mathrm{hPa})$ and two temperature sensors. The data were sampled every $15^{\prime}$ and transmitted by the ARGOS satellite data collection system. The temperature sensors are small thermistors (YSI microbeads), with an accuracy of $0.25 \mathrm{~K}$. The sensors are mounted $180^{\circ}$ apart on a $1-\mathrm{m}$ boom, hanging $5 \mathrm{~m}$ below the gondola. The thermistors are heated by the sun during day and consequently the daytime temperature observations exhibit a warm bias. This bias has been corrected as in Hertzog et al. (2004). On the Hibiscus flights, two kinds of thermistors were used: $120 \mu \mathrm{m}$ diameter and $240 \mu \mathrm{m}$ diameter. As expected, the temperatures measured with the largest thermistors have a larger bias than those measured with the smallest one due to larger radiative cooling and heating (Fig. 1). Night time temperatures measured with the largest sensor are also colder than those measured with the smallest one. This is due to the sensor radiative cooling, which scales as the square of the sensor diameter. With these two sizes, it is possible to roughly estimate the cold bias of the small thermistors night time temperatures as $0.1 \mathrm{~K}$. This small bias is neglected hereinafter and the night time temperatures measured with the small sensors are used in this paper as a reference.

The MIR balloon (Pommereau and Hauchecorne, 1979) is a hot air balloon heated by solar radiation during daytime and infrared radiation from the Earth during night-time. Therefore its altitude varies from around $15 \mathrm{hPa}(27 \mathrm{~km})$ during the day to $40-80 \mathrm{hPa}(22-18 \mathrm{~km})$ at night depending on the cloud cover, except during the first 3 days before the complete escape of helium used for the initial ascent, when the MIR could be as high as $4 \mathrm{hPa}$. The position and thus the wind are obtained from GPS just like for the BP balloons. The MIR temperatures have not been used in the present study limited to altitudes close to the tropopause.

Table 1 gives some information on the flights. Among the 6 BPs, one (BP1) was leaking and fell after 13 days. All others stayed in flight until the end of their batteries between 27 and 80 days depending on the energy consumption of the additional passenger payload flown. The three flights BP5, BP7, and BP8 are closest to the tropical tropopause and their average tropical temperatures are 198-199 K. Among the 3 MIR flown, 2 dropped after 7 and 9 days over the South Pacific Convergence Zone. The third flew for 39 days for one and a half circumnavigation of the earth between 20 and $10^{\circ} \mathrm{S}$. 
Table 1. Bauru 2004 long-duration balloon flight data: Start and end day and duration of the part used in the calculations is given. 10-90\% quantiles of the pressures and latitude ranges are shown. Mean wind speed for the BP flights is given in last column. Values for the tropical part of BP5-8 are in parenthesis.

\begin{tabular}{|c|c|c|c|c|c|c|}
\hline Flight & Start & End & Duration (days) & $\begin{array}{l}\text { Pressure (hPa) } \\
(10-90 \% \text { quantile) }\end{array}$ & $\begin{array}{l}\text { Latitude } \\
\left({ }^{\circ} \mathrm{S}\right)\end{array}$ & Mean wind $(\mathrm{m} / \mathrm{s})$ \\
\hline BP1 & $6 \mathrm{Feb}$ & 19 Feb & 12.42 & $54-55$ & $20-24$ & 10.5 \\
\hline $\mathrm{BP} 4$ & $29 \mathrm{Feb}$ & 19 May & 79.00 & $52-54$ & $12-24$ & 11.2 \\
\hline BP5 & 6 March & $\begin{array}{l}14 \text { April } \\
\text { (10 April) }\end{array}$ & $38.67(4.25)$ & $73-84(73-75)$ & $21-79(27)$ & $11.9(9.5)$ \\
\hline BP6 & 7 March & $\begin{array}{l}2 \text { May } \\
\text { (17 March) }\end{array}$ & $55.58(10.17)$ & $58-64(57-59)$ & $21-76(28)$ & $14.8(9.0)$ \\
\hline BP7 & 10 March & $\begin{array}{l}6 \text { April } \\
\text { (18 March) }\end{array}$ & $26.92(8.58)$ & $74-85(73-75)$ & $20-77(27)$ & $14.2(8.5)$ \\
\hline BP8 & 11 March & $\begin{array}{l}5 \text { April } \\
\text { (18 March) }\end{array}$ & $24.50(6.58)$ & $69-79(68-71)$ & $18-(27)$ & $14.8(10.0)$ \\
\hline MIR SAOZ1 & $6 \mathrm{Feb}$ & $14 \mathrm{Feb}$ & 8.67 & $15-45$ & $18-23$ & 26.0 \\
\hline MIR SAOZ2 & $27 \mathrm{Feb}$ & 5 April & 37.92 & $16-41$ & $8-22$ & 15.4 \\
\hline MIR mLidar & 11 March & 19 March & 7.25 & $13-29$ & $21-24$ & 19.4 \\
\hline
\end{tabular}
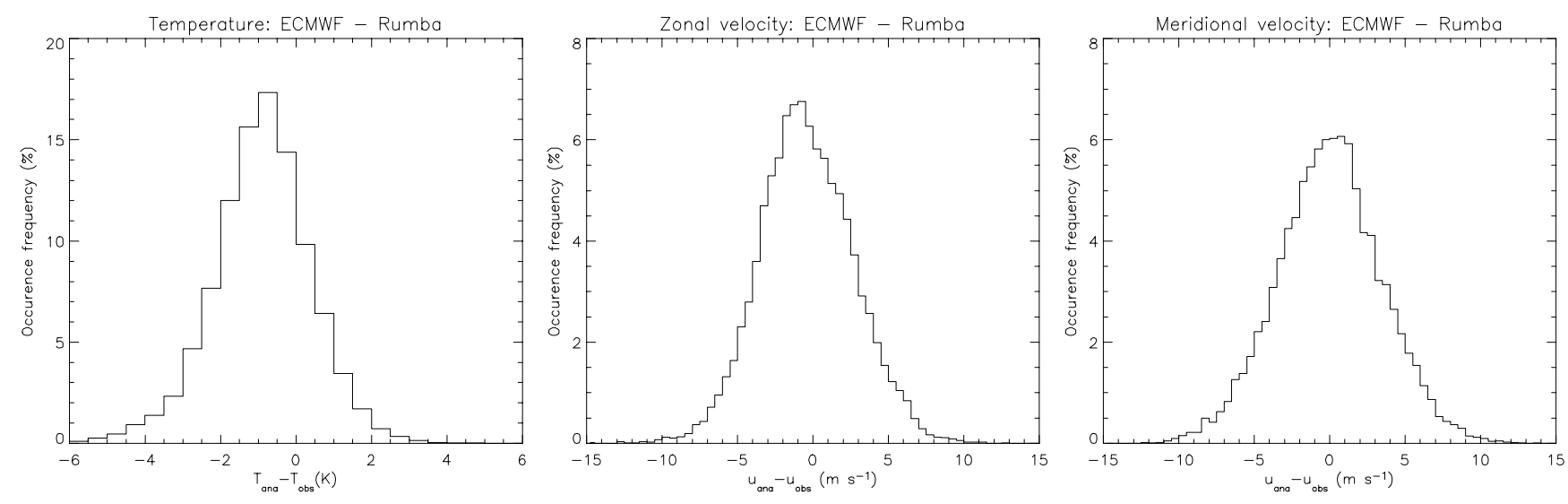

Fig. 2. Histograms of differences between ECMWF analyses and Rumba observations (analyzed - observed): (left) temperature, (center) zonal velocity, (right) meridional velocity.

\section{Analyses}

The ECMWF operational analyses in 2004 are produced by a 4-D variational analysis (Rabier et al., 2000) and are used at 6 hourly resolution. ECMWF T511 fields were extracted at the 60 model levels (spacing $\sim 1.4 \mathrm{~km}$ ) in a $1.5^{\circ} \times 1.5^{\circ}$ latitudelongitude grid (from a T79 truncation) and interpolated linearly in between. The interpolation in the vertical is done log-linearly in pressure. The top level is $0.1 \mathrm{hPa}(\sim 60 \mathrm{~km})$. The integration scheme is a 2nd order Runge-Kutta scheme with a time step of $30 \mathrm{~min}$ (BP) or $10 \mathrm{~min}$ (MIR). Such an integration should give rise to much smaller errors than other errors connected to trajectory calculations such as analyses or interpolation errors (Knudsen and Carver, 1994).

The 6-hourly NCEP/NCAR reanalyses (Kalnay et al., 1996; Kistler et al., 2000), which are produced by a 3-D variational analysis, were used in a T62 truncation with 28 levels in the vertical up to $10 \mathrm{hPa}$. Contrary to the ECMWF trajectory calculation the NCEP/NCAR trajectories use cubic spline interpolation in space and time and a fourth order Runge-Kutta scheme with a time step of half an hour.

\section{Temperatures and winds}

In this section, we compare the ECMWF operational analysis with the observations gathered during the BP flights by the Rumba gondola. The Rumba temperature measurements on the BP balloons shows a warm bias during daytime, which has been corrected. Figure 2 shows the histogram of differences between ECMWF and observed temperature, zonal and meridional wind using 6-hourly ECMWF data. The 


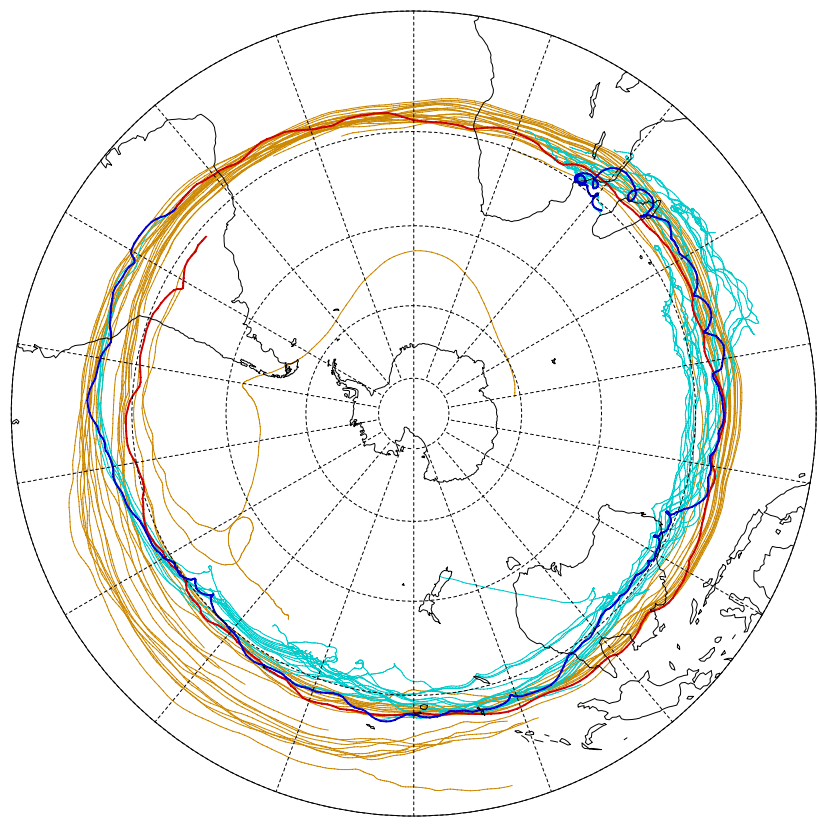

Fig. 3. BP4 flight track (thick red: 1st revolution, blue: 2nd revolution) along with 24 hourly calculated trajectories up to 20 days duration (orange: 1 st revolution, cyan: 2 nd revolution).

mean bias of ECMWF relative to the balloon measurements is $-0.9 \mathrm{~K}$ and the standard deviation is $1.3 \mathrm{~K}$ independent of whether it is from day or night and tropics or mid-latitudes. This cold bias of the ECMWF temperatures is in agreement with comparisons to radiosondes at $100 \mathrm{hPa}$ and started already in the 1998 analyses (Simmons, 2003). The bias is also seen in comparisons with GPS-derived temperatures (Gobiet et al., 2005). Vial et al. (2001) found a warm bias of about $0.5 \mathrm{~K}$ around 1 September 1998 , at $60 \mathrm{hPa}(20 \mathrm{~km})$. This does not disagree with the present results since the flights they studied were closer to the equator. Actually Gobiet et al. (2005), who used GPS-derived temperatures, also indicate a warm bias at $20 \mathrm{~km}$ close to the equator.

The ECMWF zonal (meridional) velocity has a mean bias of $-0.4(0.0) \mathrm{m} / \mathrm{s}$ and a standard deviation of $3.1(3.5) \mathrm{m} / \mathrm{s}$. If the comparison is limited to the data collected in the tropics $\left(0-30^{\circ} \mathrm{S}\right)$, the bias of the zonal velocity is $-0.7 \mathrm{~m} / \mathrm{s}$, indicating that the ECMWF tropical easterlies are too strong. A spectral analysis (not shown) has shown that much of the scatter in these comparisons is due to meso- and short-scale inertia-gravity waves, which the ECMWF analysis has difficulties in capturing. These waves are more frequent at the tropical tropopause than above.Several factors can explain that the inertia-gravity waves are not well represented by ECMWF: The first is that at the BP flight altitude, the ECMWF vertical resolution was about $1 \mathrm{~km}$ in 2004, while the dominant vertical wavelength of gravity waves in the lower stratosphere is about $2 \mathrm{~km}$. The vertical resolution was thus a bit too short to fully resolve those waves. The sec- ond is that analysis outputs are stored every $6 \mathrm{~h}$, which is an undersampling of the model time resolution. Gravity waves, which have periods of about 1 day, may be damped by this undersampling. The third is that a major source of gravitywaves in the tropics is convection, which is parameterized in the ECMWF model, so that the model may miss the physical processes that generate the waves.

\section{Trajectories}

To assess how accurate calculated trajectories are, trajectory calculations (Knudsen et al., 2001; Knudsen and Carver, 1994; Hertzog et al., 2004) were started every $2 \mathrm{~h}$ along the flight track. In each time step the trajectories calculated for the BP flights were forced to a pressure lying on the same isopycnic (constant density) surface as the balloon. Thereby the vertical motion of the trajectories is taken care of. The trajectories for the MIR flights were forced to balloon pressure. Figure 3 shows the flight track for the 79 day long BP4 flight, and every 12th of the calculated trajectories. Most calculated trajectories stay in the tropical reservoir (i.e. the region between the northern and southern tropical edges) except for a few. One of the trajectories even moves to the Antarctic, just like some of the other BP balloons did. This does not necessarily indicate that the analyzed tropical barrier is leakier than the real, since trajectory errors could bring the calculated trajectories to regions where transport out of the tropical reservoir does occur. In agreement with the previous section, this figure also shows that the major part of the wave perturbations seen on the BP4 trajectory is not caught by the ECMWF analyses. We have tried to run trajectories at the highest possible resolution $\left(0.5^{\circ} \times 0.5^{\circ}\right.$ from a T511 truncation) for the second revolution of the balloon (not shown). This leads to small changes in the calculated trajectories, but the major part of the wave pertubations are still not cought.

The horizontal balloon velocity is a very good approximation of the horizontal air velocity (Vial et al., 2001). In order to mimic the balloon behaviour in the vertical, isopycnic trajectories were computed for BP, while MIR trajectories were obtained by forcing the pressure to the observed balloon pressure. With this method only horizontal trajectory errors can be addressed, but these are in fact the most important ones if the vertical transport is calculated with a state-of-the-art radiation code (Knudsen et al., 2001).

Special attention has been attributed to the 79 day long BP4 flight, which remained in the tropics. Figure 4 shows the average spherical distance between the calculated and observed trajectory as a function of trajectory duration. The standard error on the average is calculated with lag $2 \mathrm{~h}$ autocorrelations taken into account and are indicated by the shading. The errors for the NCEP/NCAR reanalyses are based on trajectories started every $12 \mathrm{~h}$ and are calculated under the assumption that the autocorrelations are the same as for the ECMWF trajectories. The NCEP/NCAR reanalyses 


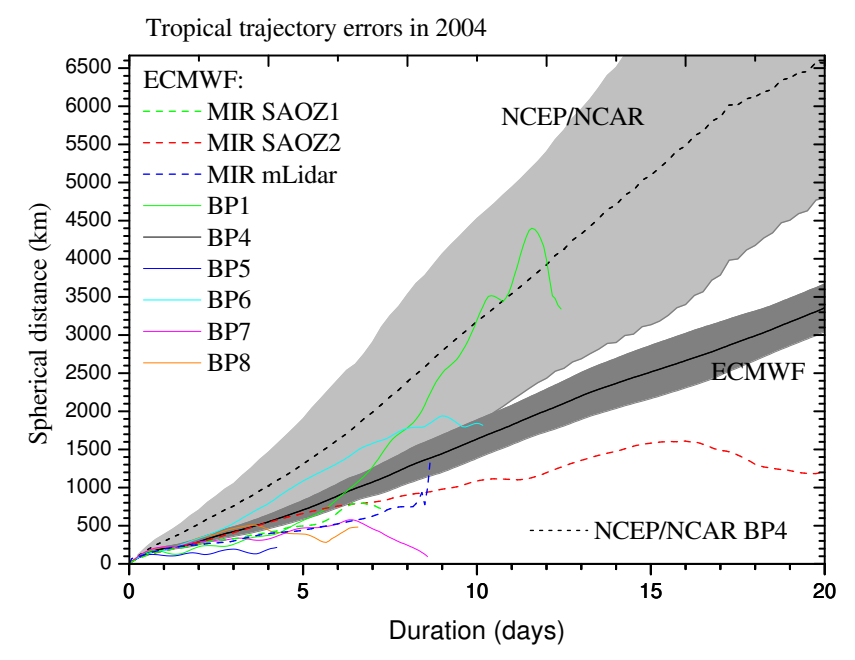

Fig. 4. Mean tropical trajectory errors for the 2004 flights. Dark and light grey shading gives $68 \%$ confidence limits on the means for BP4 using ECMWF and NCEP/NCAR reanalysis, respectively. The BP flight level usually is $52-75 \mathrm{hPa}$, whereas the MIR flight level usually is $13-45 \mathrm{hPa}$.

trajectory errors are larger than the ECMWF errors at the $68 \%$ confidence level except for durations of 5.25-8.25 days, even though the shadings overlap. For durations larger than about 10 days the shadings do not overlap indicating that the differences are significant with more than $68 \%$ confidence. The difference is only significant at the $95 \%$ confidence level for a duration of $12 \mathrm{~h}$. The coarse vertical resolution of the NCEP/NCAR reanalyses could be responsible for the differences. Another contributing factor could be increased dynamical consistency of the ECMWF 4-D variational data assimilation, where departures of observations from a forecast in a $12 \mathrm{~h}$ time window are minimized.

Figure 4 also shows the trajectory errors for all other flights in 2004. The balloons leaving the tropics were only used until the zero wind line was crossed at about $27^{\circ} \mathrm{S}$. The MIR data are only used after the time when the pressure permanently is larger than $10 \mathrm{hPa}$ (except that the MIR mLidar does reach a minimum pressure of $9.2 \mathrm{hPa}$ ). The MIR balloons run at higher altitudes than the BP. In the Arctic trajectory errors increase with altitude (Knudsen et al., 2001) due to e.g. the decreasing number of radiosondes and their increasing errors. Judging from the trajectory errors on the longest MIR and BP flights there is no increase with height in the tropics. This result could, however, be influenced by the reduced occurrence of atmospheric waves, which ECMWF has difficulties in catching, along the higher-altitude MIR flights. The longest MIR and BP flights have 3.7 times more calculated trajectories of duration 5 days than all the other flights together. Therefore we can concentrate on these two longest flights. The results of the other flights do not seem to be significantly different due to the large confidence limits on

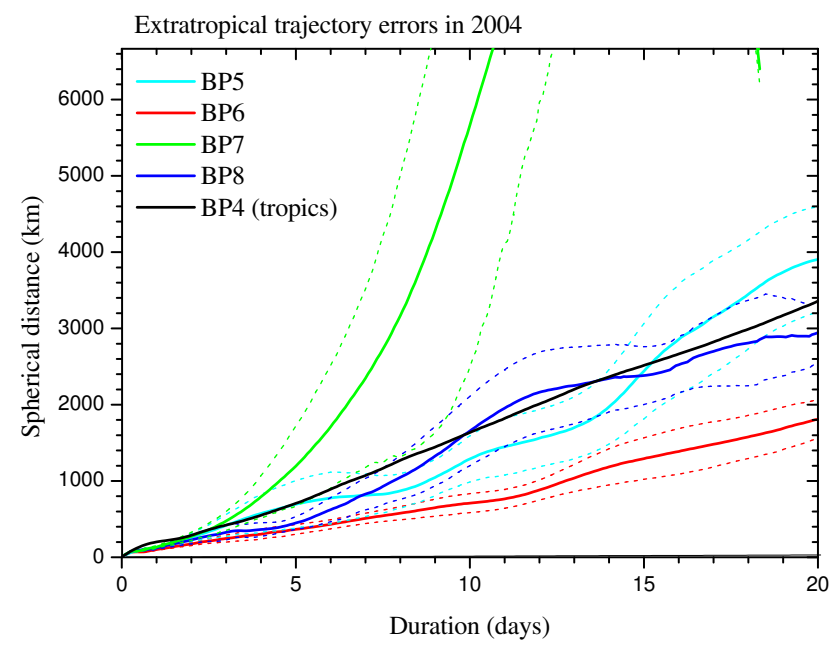

Fig. 5. Mean extra-tropical trajectory errors for the 2004 flights. Thin dashed lines give $68 \%$ confidence limits on the means. For comparison the tropical flight BP4 is included.

these other flights. The trajectory error in the zonal (meridional) direction is defined as the spherical distance at fixed balloon latitude (longitude). For the BP4 flight the trajectory errors are a factor of 2.4 larger in the zonal direction than in the meridional direction after 5 days. This is partially caused by the bias in the zonal wind.

In the Arctic the trajectory errors are approximately halved being about $270 \mathrm{~km}$ after 5 days (Hertzog et al., 2004). This is primarily due to the bias in the meridional wind. This bias may be due to the reduced number of radiosondes and the break-down of geostrophy in the Tropics, which makes it difficult to transform satellite observations of temperature related quantities to winds. In principle it should be possible to correct for such a bias and thereby reduce the trajectory errors. In the Arctic wind speeds are much larger, so trajectory errors relative to the trajectory length (Relative Spherical Distance $=$ RSD) are much smaller.

The trajectory errors after $2 \mathrm{~h}$ are a good measure of the errors of the vector wind. For the tropical part of the BP flights it can be transformed to an average vector wind difference of $-0.86 \mathrm{~m} / \mathrm{s}$, which agrees quite well with the results found in Sect. 4. For the MIR flights the result is $-0.58 \mathrm{~m} / \mathrm{s}$, indicating a slightly reduced wind error at higher altitudes in the lower stratosphere.

Figure 5 shows the spherical distance between the calculated and observed trajectories for the extratropical part of the flights BP5-8 (i.e. after the time when the zonal wind turned zero). The calculated trajectories were cut-off at $79.5^{\circ} \mathrm{S}$. In case of missing trajectories due to this cut-off uncertainties were not calculated. The last 12.75 days of the BP8 flight were removed to avoid trajectories to be cut-off. For the BP5 flight the trajectory errors are comparable to the tropical errors for BP4 for trajectory durations up to 5 days. Much 


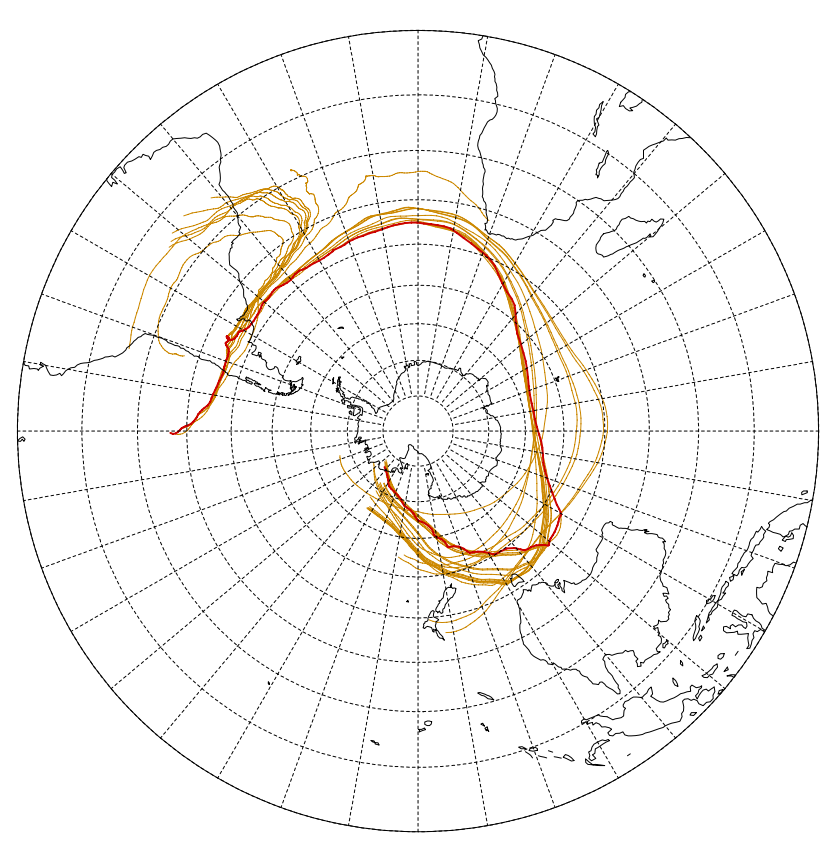

Fig. 6. BP7 extratropical flight track (thick red line) along with 12 hourly calculated trajectories (thin orange lines).

larger errors occur for the BP7 flight. As seen on Fig. 6 this is due to a substantial part of the calculated trajectories staying in the tropics, whereas the balloon moves towards the South Pole. These trajectories of course have very large errors, but the average error is in fact not significantly larger than the errors of the other flights at $95 \%$ confidence due to very large error bars.

Trajectories close to a flow barrier like the tropical barrier can thus have large errors, because unavoidable small errors can push the calculated trajectory to the wrong side of the barrier or the barrier can be misplaced in the analyses. In this case the trigger was probably a situation with very low wind speeds as depicted in Fig. 7. New trajectories were started every $12 \mathrm{~h}$ from the red crosses. The balloon makes a loop, which is not caught by the ECMWF trajectories. The arrows show the $80 \mathrm{hPa}$ wind field at the time when the balloon passes the cross in the loop. Situations of low wind speeds are critical for trajectory calculations since the errors on the analyzed wind do not go to zero as the wind speed does (Knudsen et al., 2001). Most of the trajectories started before or during the loop thus take a more northerly course and end up in the tropics, while most of the trajectories started afterwards move towards the South Pole. Most of the other balloon flights also encountered low wind speeds, but this did not lead to so large trajectory errors because it did not push such a large number of trajectories to the wrong side of a flow barrier.

The ECMWF reanalysis, ERA-40, temperatures show a smaller systematic cold bias around $60 \mathrm{hPa}$ of $0.5 \mathrm{~K}$ compared to long-duration balloon flights close to the equator

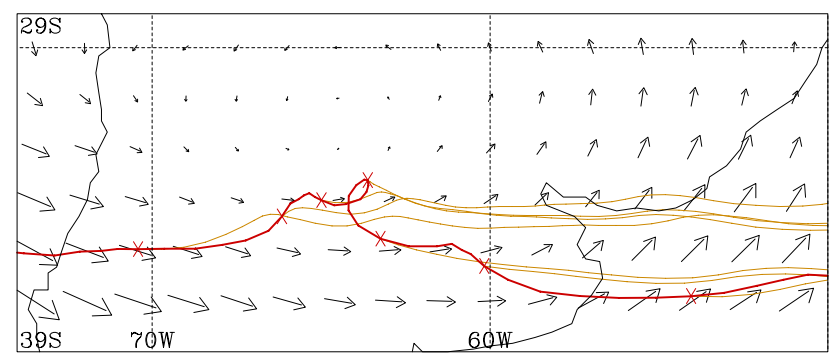

Fig. 7. Close-up of the BP7 flight track when passing South America (thick red line) and 12 hourly calculated trajectories (thin orange lines) started from the red crosses. Horizontal winds are shown as arrows with a scale such that the north-south distance between the arrow centres equals $20 \mathrm{~ms}^{-1}$.

in 1998 (Christensen et al., 2006 ${ }^{2}$ ). For these flights the trajectory errors are about $1000 \mathrm{~km}$ after 5 days, which is possibly due to Rossby-gravity waves which ERA-40 is unable to catch. Flights at higher altitudes have trajectory errors of about $500 \mathrm{~km}$ after 5 days, which is more in line with the results for the ECMWF operational analyses shown in this paper.

\section{Conclusions}

The ECMWF operational temperatures in 2004 show a systematic cold bias of $0.9 \mathrm{~K}$ just above the tropical tropopause $(50-80 \mathrm{hPa})$. The easterly zonal winds in this region are too strong by $0.7 \mathrm{~m} / \mathrm{s}$. In the southern extratropics the temperature bias is the same and the zonal wind has almost no bias. After 5 days the average trajectory error is about $500 \mathrm{~km}$, when discarding one balloon flight with very large errors. This is true for both the tropics and southern extratropics and also for tropical flights at about $13-45 \mathrm{hPa}$. The absolute trajectory errors are not much larger than the errors in the Arctic, but there the wind speeds are much larger.

Acknowledgements. ECMWF and NCAR/NCEP are thanked for supplying meteorological data. The balloons were operated by the Centre National d'Etudes Spatiales in cooperation with the Institute of Meteorology of the State University of Sao Paulo in Brazil, which are gratefully acknowledged. This work was done within the HIBISCUS and SCOUT-O3 projects funded by the European Commission.

Edited by: R. MacKenzie

\section{References}

Gobiet, A., Foelsche, U., Steiner, A. K., Borsche, M., Kirchengast, G., and Wickert, J.: Climatological validation of stratospheric temperatures in ECMWF operational analyses with CHAMP radio occultation data, Geophys. Res. Lett., 32, L12806, doi:10.1029/2005GL022617, 2005. 
Hertzog, A., Basdevant, C., Vial, F., and Mechoso, C. R.: Some results on the accuracy of stratospheric analyses in the Northern Hemisphere inferred from long-duration balloon flights, Quart. J. Roy. Meteorol. Soc., 129, 607-626, 2004.

Kalnay, E., Kanamitsu, M., Kistler, R., et al.: The NCEP/NCAR 40year reanalysis project, Bull. Am. Meteorol. Soc., 77, 437-471, 1996.

Kistler, R., Kalnay, E., Collins, W., et al.: The NCEP-NCAR 50year reanalysis: Monthly means CD-ROM and documentation, Bull. Am. Meteorol. Soc., 82, 247-267, 2000.

Knudsen, B. M., Pommereau, J.-P., Garnier, A., Nunez-Pinharanda, M., Denis, L., Letrenne, G., Durand, M., and Rosen, J. M.: Comparison of stratopheric air parcel trajectories based on different meteorological analyses, J. Geophys. Res., 106, 3415-3424, 2001.

Knudsen, B. M. and Carver, G. D.: Accuracy of the isentropic trajectories calculated for the EASOE campaign, Geophys. Res. Lett., 21, 1199, 1994.

Pommereau, J.-P. and Hauchecorne, A.: A new atmospheric vehicle: la Mongolfière infrarouge, Adv. Space Res., 55, 1979.

Rabier, F., Järvinen, H., Klinker, E., Mahfouf, J.-F., and Simmons, A.: The ECMWF operational implementation of four dimensional variation assimilation. I: Experimental results with simplified physics, Quart. J. Roy. Meteorol. Soc., 126, 1143-1170, 2000 .
Randel, W. J., Wu, F., Oltmans, S. J., Rosenlof, K., and Nedoluha, G. E.: Interannual Changes of Stratospheric Water Vapor and Correlations with Tropical Tropopause Temperatures, J. Atmos. Sci., 61, 2133-2148, 2004b.

Randel, W., Udelhofen, P., Fleming, E., Geller, M., Gelman, M., Hamilton, K., Karoly, D., Ortland, D., Pawson, S., Swinbank, R., Wu, F., Baldwin, M., Chanin, M.-L., Keckhut, P., Labitzke, K., Remsberg, E., Simmons, A., and Wu, D.: The SPARC Intercomparison of Middle-Atmosphere Climatologies, J. Climate, 17, 986-1003, 2004a.

Simmons, A.: Representation of the stratosphere in ECMWF operations and ERA-40, Workshop on modelling and assimilation for the stratosphere and troposphere, Reading, 23-26 June, 2003.

Simmons, A. J., Untch, A., Jacob, C., Kållberg, P., and Undén, P.: Stratospheric water vapour and tropical tropopause temperatures in ECMWF analyses and multi-year simulations, Quart. J. Roy. Meteorol. Soc., 125, 353-386, 1999.

SPARC: Intercomparison of Middle Atmosphere Climatologies, SPARC Rep. 3, 96 pp., 2002.

Vial, F., Hertzog, A., Mechoso, C. R., Basdevant, C., Cocquerez, P., Doubough, V., and Nouel, F.: A study of the dynamics of the equatorial lower stratosphere by the use of ultra long duration balloons. Part I: Planetary scales, J. Geophys. Res., 106, 22725 $22744,2001$. 